\title{
IMPLEMENTASI DETEKSI PLAGIARISME MENGGUNAKAN METODE N-GRAM DAN JACCARD SIMILARITY TERHADAP ALGORITMA WINNOWING
}

\author{
Sunardi $^{1}$, Anton Yudhana ${ }^{2}$, dan Iif Alfiatul Mukaromah ${ }^{3 *}$ \\ Program Studi Teknik Elektro, Universitas Ahmad Dahlan ${ }^{1,2}$. \\ Program Studi Magister Teknik Informatika, Universitas Ahmad Dahlan ${ }^{3 *}$ \\ Kampus 3 UAD Jl. Prof Soepomo, Janturan, Yogyakarta, 55164, Indonesia., 2, 3 \\ E-Mail:Sunardi@mti.uad.ac.id ${ }^{l}$, eyudhana@ee.uad.ac.id ${ }^{2}$,iifam1604@gmail.com ${ }^{3 *}$
}

\begin{abstract}
Abstrak
Fenomena plagiarisme dalam dunia akademik bukanlah hal yang baru di Indonesia, perguruan tinggi di Indonesia sudah cukup lama dicemari oleh tindak plagiarisme. Dengan didukungnya kemajuan teknologi yang semakin canggih, salah satunya jaringan internet yang mendunia, memudahkan, cepat, praktis dan murah. Sehingga banyak orang lebih memilih menggunakan internet untuk menyelesaikan tugasnya seperti membuat karya ilmiah dengan cara copy-paste karya orang lain dari internet tanpa menyebutkan sumber yang digunakan untuk menyelesaikan tugasnya. Hal tersebut bisa diatasi secara dini menggunakan metode $n$-gram untuk mengambil potongan karakter huruf pada dokumen yang akan dicocokan dan Jaccard similarity untuk menghitung berapa persen kesamaan pada sebuah dokumen yang diproses menggunakan algoritma winnowing. Algoritma winnowing merupakan algoritma yang digunakan untuk mencocokan karakter huruf atau angka pada dua dokumen dengan teknik hashing.
\end{abstract}

Kata kunci: N-gram, Jaccard Similarity, Algoritma Winnowing.

\begin{abstract}
The phenomenon of plagiarism in the academic world is not new in Indonesia, universities in Indonesia have long been contaminated by the act of plagiarism. With the advancement of technological advancements that increasingly sophisticated, one of the Internet network worldwide, easy, fast, practical and inexpensive. So many people prefer to use the internet to accomplish tasks such as making scientific work by copy-pasting someone else's work from the internet without mentioning the source used to complete the task. This can be resolved early using the N-gram method to extract the chunks of the letters on the matching document and Jaccard similarity to calculate what percentage of similarity in a document is processed using winnowing algorithm. The winnowing algorithm is an algorithm used to match letters or numbers on two documents by hashing technique.
\end{abstract}

Keywords: N-gram, Jaccard Similarity, Algoritma Winnowing.

\section{Pendahuluan}

Plagiarisme merupakan tindakan kejahatan yang sudah tidak asing lagi dalam dunia akademik di Indonesia. Tindakan plagiarisme dalam kamus Inggris The Oxford Advanced Learner's Dictionary mendefinisikan plagiarisme sebagai 'to take somebody's else idea or words and use them as if they were one's own'[1]. Plagiarisme merupakan perbuatan yang tidak baik disebabkan mengambil karya (ide, gagasan, dan pikiran) orang lain tanpa izin, tanpa menyatakan karya yang diambilnya merupakan karya orang lain/tidak menyantumkan sumbernya, dan mengakui bahwa karya itu miliknya. Tindakan tersebut sama seperti tindakan mencuri.
Tindakan plagiarisme disuburkan oleh perkembangan internet sebagai teknologi yang semakin canggih, kemudahan mendapatkan suatu informasi, penggunaan yang cepat dan murah sehingga manusia lebih memilih mencari bahan atau referensi tugasnya dalam internet dibandingkan harus membeli buku. Akan tetapi banyak orang yang menyalah gunakan internet untuk hal yang negatif salah satunya yaitu mengambil karya orang lain dari internet tanpa menyatakan sumbernya[2].

Dampak buruk dari tindakan plagiarisme dapat mengakibatkan kemunduran suatu bangsa, karena tidak ada keinginan untuk maju atau memunculkan hal-hal yang baru, bahkan tindakan plagiarisme juga merupakan 
bentuk pelanggaran ketentuan dan peraturan pemerintah[1]. Untuk itu perlu adanya alat yang dapat meminimalisir atau mencegah agar tindakan mencuri karya orang lain itu tidak terulang kembali, khususnya mencegah kejahatan dalam dunia akademik.

Beberapa penelitian sebelumnya telah membuat pendeteksian plagiarisme menggunakan beberapa algoritma yang mempunyai fungsi sama sebagai document fingerprint, tetapi permasalahan yang sering terjadi pada hasil atau tingkat keakurasian [2] Penggunaan model Bayesian juga telah digunakan[3], namun tidak sepenuhnya dapat mendeteksi kemiripan. $N$ gram merupakan algoritma yang akan digunakan untuk mengambil potongan huruf sejumlah $\mathrm{n}$ dan mempunyai pengaruh yang tinggi terhadap hasil similarity[4]. Algoritma yang akan digunakan untuk mengetahui tingkat kemiripan teks atau dokumen yaitu Jaccard Similarity atau sering disebut Jaccard Coefficient.

Jaccard Similarity merupakan algoritma yang berfugsi untuk membandingkan antar dua dokumen dengan menghitung kemeripan atau perbedaan dari dokumen tersebut[5]. Untuk menjalankan n-gram dan Jaccard Similarity diperlukan algoritma yang berfungsi sebagai document fingerprint dan algoritma yang akan digunakan untuk mendukung tersebut yaitu algoritma winnowing. Algoritma winnowing merupakan algoritma yang dapat digunakan untuk membantu mendeteksi kemiripan kata atau dokumen yang akan digunakan sebagai suatu cara untuk mendeteksi adanya suatu tindak plagiariasme[6]. Diharapkan dengan adanya alat pendeteksi plagirisme menggunakan metode $n$-gram dan Jaccard similarity terhadap algoritma winnowing dapat memberikan keakurasian yang tepat dan mengatasi tindakan suatu plagiarisme yang terjadi di dunia akademik maupun dunia non akademik.

\section{Metode}

\subsection{N-Gram}

$N$-gram merupakan metode yang yang dilakukan dengan mengambil rangkaian substring dari string sejumlah $\mathrm{n}$ (rangkaian token sepanjang $\mathrm{n}$ )[7]. Metode $n$-gram sering digunakan pada teknik analisis statistik dan juga bahasa[8]. Dalam game $n$-gram digunakan untuk action prediction dengan mengambil rangkain aksi player sejumlah yang ditentukan dalam aksi player secara berkelanjutan[8]. Akan tetapi n-gram paling banyak digunakan dalam teks mining (pengolahan kata) dan pengolahan bahasa. Dalam mendeteksi plagiarisme, $n$ gram digunakan untuk mengambil potongan-potongan karakter huruf atau pemisahan string sepanjang $\mathrm{n}$ dari sebuah kata atau dokumen secara berkelanjutan (kontinuitas) hingga bergeser sesuai dengan offsite yang diberikan atau akhir dari suatu kata atau dokumen[7][9].

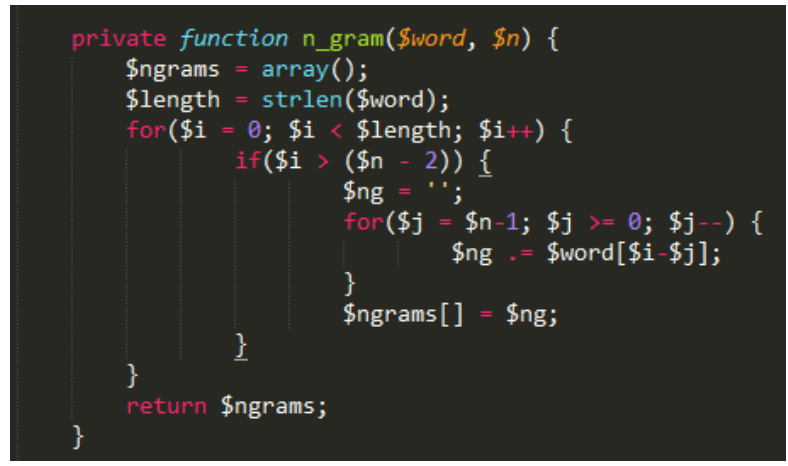

Gambar 1. Program N-gram

Gambar 1 merupakan program PHP dari n-gram dimana dokumen atau sekumpulan kata akan diproses dan akan dibentuk sebanyak $n$-gram atau memisahkan string sepanjang $\mathrm{n}$ yang akan dihitung pergeserannya secara terus menurus ke depan sejumlah nilai $\mathrm{n}$ sampai akhir dokumen. Sebagai contoh $n$-gram dari kata "Magister Teknik Informatika" dengan nilai $\mathrm{N}=4$ maka (magi agis gist iste ster tert erte rtek tekn ekni knik niki ikin kinf info nfor form orma rmat mati atik tika).

$N$-gram dalam deteksi plagiarisme sangat mempengaruhi tingkat akurasi atau tingkat similarity dari sebuah dokumen yang dibandingkan, maka teknik n-gram dipadukan dengan pendekatan statistika untuk memperoleh similarity dari antar dokumen seperti Simple Matching, Cosine Similarity, Jaccard Similarity dan Dice Coefficient. Ada 2 (dua) teknik $n$-gram yaitu membagi string menjadi suatu set substring dengan panjang $\mathrm{n}$ (overlapping $n$-gram) dan mengecek untuk membentuk subtstring yang memiliki struktur yang sama[9].

\subsection{Jaccard Similarity}

Jaccard Similarity atau Jaccard Coefficient merupakan algoritma yang fungsinya untuk membandingkan dua sample yaitu dokumen yang satu dengan yang lainnya berdasarkan kata yang dimilikinya. Jaccard similarity biasanya digunakan untuk membandingkan dokumen dan menghitung nilai kemiripan (similarity) dari dua buah objek atau dokumen[5][10][11]. Jaccard similarity dapat dirumuskan sebagai berikut:

$$
\operatorname{Similarity}(X, Y)=\frac{|\mathrm{X} \cap \mathrm{Y}|}{|X \cup Y|}
$$

Dimana:

$$
\begin{array}{ll}
\mathrm{X} & =\text { Dokumen 1 } \\
\mathrm{Y} & =\text { Dokumen 2 }
\end{array}
$$

Rumus 1 merupakan dari rumus Jaccard Similarity atau Jaccard Coefficient yang digunakan untuk mencari persamaan dan perbedaan pada dua sample. sebagai contoh diketahui $\mathrm{X}$ "Magister Teknik Informatika 
Yogyakarta", dan Y "Magister Teknik Sipil Yogyakarta”. Maka akan menghasilkan nilainya:

$$
\begin{aligned}
& \text { Similarity }(X, Y)=\frac{\mid \text { Magister Teknik Yogyakarta } \mid}{\mid \text { Magister Teknik Informatika Sipil Yogyakarta } \mid} \\
& \text { Similarity }(X, Y)=\frac{3}{5}=0,6 \times 100 \%=60 \%
\end{aligned}
$$

Dari dua contoh sample di atas setelah dihitung kesamaannya menggunakan Jaccard similarity, bahwa kedua sample tersebut memiliki kesamaan atau kemiripan sebesar $60 \%$. Di bawah ini merupakan program dari Jaccard similarity atau Jaccard Coefficient.

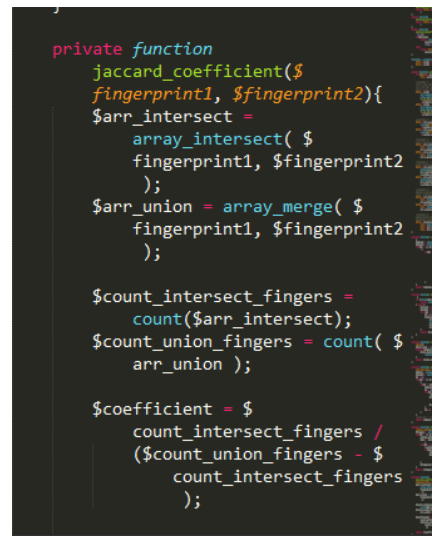

Gambar 2. Potongan Program dari Jaccard Similarity atau Jaccard Coefficient

Gambar 2 menunjukan potongan program yang akan di gunakan untuk perhitungan drajat kesamaan atau untuk mengecek suatu kemirian pada dua buah sample atau dokumen menggunakan Jaccard Similarity atau Jaccard Coefficient.

Ukuran tingkat kesamaan [12]:
a. $0 \%$ : dua dokumen tidak memiliki kesamaan
b. $<15 \%$ : memiliki sedikit kesamaan
c. $15-50 \%$ : termasuk dalam katagori plagiarisme sedang
d. $50 \%$ : mendeteksi adanya plagiarisme
e. $100 \%$ : dokumen tersebut plagiarisme

\subsection{Algorirma Winnowing}

Algoritma winnowing merupakan salah satu algoritma yang berfungsi sebagai document fingerprint atau algoritma yang digunakan untuk mendeteksi tindakan plagiarisme dengan menggunakan teknik hashing. Input dari algoritma winnowing berupa dokumen teks, dan akan menghasilkan keluaran berupa kumpulan nilai hash yang terbentuk dari peritungan ASCII pada setiap karakter. Dan nilai-nilai hash yang akan digunakan sebagai fingerprint untuk mendeteksi adanya suatu tindakan plagiarisme [13][14]. Gambar 3 merupakan konsep algoritma winnowing.

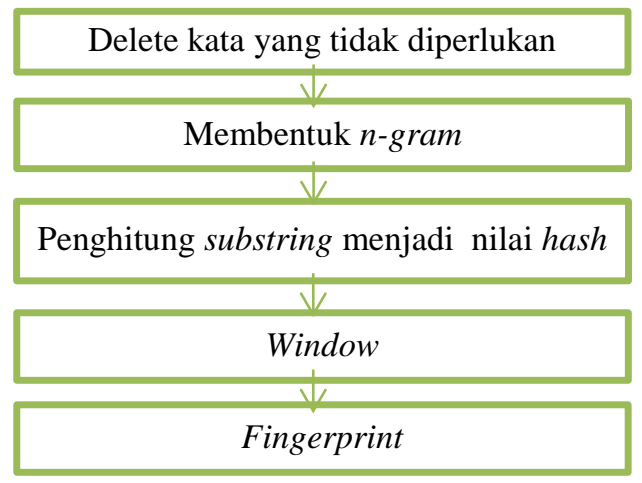

Gambar 3. Konsep Algoritma Winnowing

Konsep dari algoritma winnowing yang ditujukan pada gambar 3 yaitu menghapus karakter yang tidak relevan, membentuk $n$-gram dengan panjang $\mathrm{n}$, menghitung nilai hash, membentuk nilai window, dan memilih nilai hash sebagai document fingerfrint[6]. Nilai hash didapatkan dari rumus Rolling hash.

Rolling hash adalah metode hashing yang digunakan untuk mencari nilai hash dari rangkaian grams yang telah terbentuk dan memberikan kemampuan untuk menghitung nilai tanpa mengulangi seluruh string. Nilai hash merupakan nilai numerik yang dibentuk dari kode ASCII[15].

Berikut rumus rolling hash

$H\left(C_{1 . .} C_{l}\right)=C_{1} \cdot b^{(l-1)}+C_{2} \cdot b^{(l-2)}+\ldots+C_{(l-1)} \cdot b+C_{l}$

$H\left(c_{2} \ldots . . c_{l+1}\right)=\left(H\left(c_{1} \ldots c_{l}\right)-c_{1} * b^{(l-1)}\right) * b+c^{(l-1)}$

Dimana:

$H\left(C_{l} . . C_{l}\right) \quad=$ nilai hash

$C_{l} \quad=$ nilai ASCII karakter ke -1 pada string

$l \quad=$ panjang string

$b \quad=$ nilai basis hash

Perhitungan awal pada rangkaian n-gram paling awal dihitung menggunakan rumus nomer 2 , dan rangkaian ngram berikutnya sampai rangkaian gram terakhir di hitung menggunakan rumus nomer 3, sehingga proses akan jauh lebih cepat karna tidak menghitung lagi dari awal.

Algoritma winnowing merupakan eksitensi dari algoritma Rabin-karp, proses yang dilakukan hampir sama hanya pada algoritma winnowing ditambahkan dengan konsep window.

\subsection{Perancangan Sistem}

Perancangan Sistem yang akan digunakan untuk membuat aplikasi deteksi plagiarisme menggunakan metode $n$-gram dan Jaccard similarity atau Jaccard coefficient terhadap algoritma winnowing. 


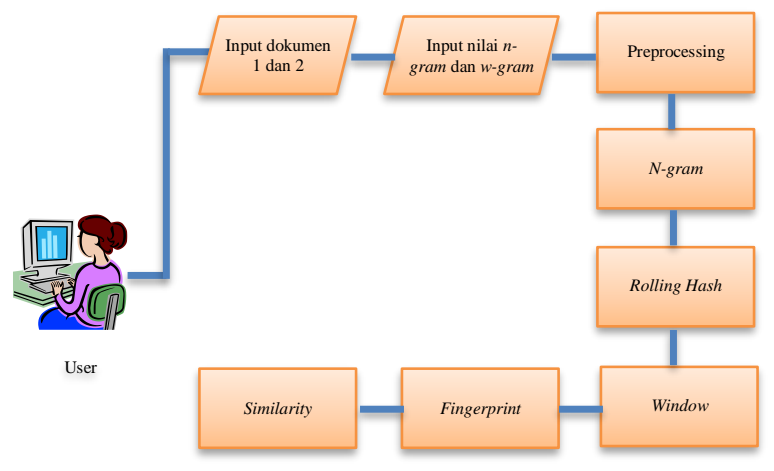

Gambar 4. Tahapan Algoritma Winnowing

Gambar 4 merupakan tahapan algoritma winnowing, pada awal antarmuka user diperlukan untuk memasukan dokumen atau teks yang akan digunakan sebagai pembanding dan dokumen yang akan dibandingkan, kemudian user diminta untuk menginputkan nilai $n$-gram dan $w$-gram yang akan digunakan untuk memproses dari algoritma winnowing. Pada tahap selanjutnya yaitu pemisahan karakter yang tidak relevan atau sering disebut dengan tahap preprocessing, pada tahap ini akan dihilangkan karakter yang tidak diperlukan seperti spasi, tanda baca (Tokenizing) dan merubah huruf kapital menjadi huruf kecil (case Folding). Selanjutnya sistem akan membentuk nilai $n$-gram sepanjang $\mathrm{n}$, potongan karakter yang diambil sepanjang $\mathrm{n}$ akan dihitung untuk dicari nilai hash dengan menggunakan rumus rolling hash. Nilai-nilai hash yang sudah terbentuk, maka tahap selanjutnya yaitu tahap algoritma winnowing (pembentukan window atau w-gram) yang akan digunakan untuk mencari atau memilih fingerprint. Tahap terakhir yaitu penggunaan Jaccard similarity digunakan untuk membandingkan dari kedua dokumen atau sample.

\section{Hasil dan Analisa 3.1. Uji Coba}

Hasil uji coba dari pendeteksi plagiarisme menggunakan metode n-gram dan Jaccard Similarity atau Jaccard Coefficient terhadap algoritma winnowing akan di tampilkan pada tabel 1 dengan menggunakan $n$-gram dan $w$-gram yang berbeda-beda.

Tabel 1 menjelaskan pengaruh dari penggunaan $n$-gram dan $w$-gram terhadap hasil similarity. Hasil pengujian terhadap dua sample atau dokumen pada tabel 1 dengan nilai $n$-gram dan $w$-gram yang berbeda memiliki drajat kesamaan yang berbeda-beda. Semakin kecil nilai $n$-gram dan w-gram maka drajat kesamaan atau similarity terhadap dua dokumen mempunyai drajat kesamaan yang tinggi, sedangkan jika semakin besar nilai $n$-gram dan $w$ gram maka drajat kesamaan pada dua dokumen itu memiliki drajat yang rendah, jika nilai $n$-gram dan $w$ gram sama. Pada tabel 1 membuktikan $n$-gram dan $w$ gram dengan nilai 3 menghasilkan similarity $35 \%$, sedangkan $n$-gram dan w-gram dengan nilai 6 menghasilkan similarity yang rendah yaitu $18,18 \%$. Uji coba pada tabel 1 nomer 2 dan 3 menghasilkan drajat kesamaan atau similarity yang jauh lebih tinggi dari pada pengujian pada nomer 1 . Penginputan nilai yang berbeda pada nilai $n$-gram dan $w$-gram dapat menghasilkan nilai similarity yang tinggi. Semakin kecil nilai $n$-gram dan $w$ gram maka akan semakin sering potongan itu akan dicocokan dan sering ditemukan, jika sebaliknya maka akan semakin jarang data itu dicocokkan atau di temukan.

Table 1. Uji Coba Pendeteksi Plagiarisme Menggunakan $N$ gram dan W-gram yang berbeda Terhadap Hasil Similarity dengan Metode Jaccard Similarity

\begin{tabular}{|c|c|c|c|c|c|}
\hline \multirow{2}{*}{ No } & \multicolumn{2}{|c|}{ Input Dokumen } & \multirow[b]{2}{*}{ N-gram } & \multirow[b]{2}{*}{ W-gram } & \multirow{2}{*}{ Similarity } \\
\hline & Kalimat 1 & Kalimat 2 & & & \\
\hline 1. & $\begin{array}{l}\text { Magister Teknik } \\
\text { Elektro }\end{array}$ & $\begin{array}{l}\text { Magister Teknik } \\
\text { Informatika }\end{array}$ & 3 & 3 & $35,71 \%$ \\
\hline 2. & $\begin{array}{l}\text { Magister Teknik } \\
\text { Elektro }\end{array}$ & $\begin{array}{l}\text { Magister Teknik } \\
\text { Informatika }\end{array}$ & 5 & 3 & $41,67 \%$ \\
\hline 3. & $\begin{array}{c}\text { Magister Teknik } \\
\text { Elektro }\end{array}$ & $\begin{array}{l}\text { Magister Teknik } \\
\text { Informatika }\end{array}$ & 4 & 5 & $45,45 \%$ \\
\hline 4. & $\begin{array}{l}\text { Magister Teknik } \\
\text { Elektro }\end{array}$ & $\begin{array}{l}\text { Magister Teknik } \\
\text { Informatika }\end{array}$ & 4 & 4 & $41,67 \%$ \\
\hline 5. & $\begin{array}{c}\text { Magister Teknik } \\
\text { Elektro }\end{array}$ & $\begin{array}{l}\text { Magister Teknik } \\
\text { Informatika }\end{array}$ & 6 & 6 & $18,18 \%$ \\
\hline
\end{tabular}

\subsection{Implementasi}

Berikut adalah implementasi deteksi plagiarisme pada dunia tulis-menulis dengan menggunakan metode $n$-gram dan Jaccard Similarity atau Jaccard Coefficient terhadap algoritma winnowing. Gambar 5 merupakan proses yang digunakn user untuk menginputkan dokumen yang akan dibandingkan.

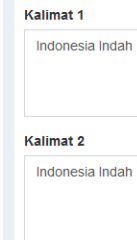

\section{Gambar 5. Input Dokumen}

Gambar 5 menunjukan antarmuka pertama dari algoritma winnowing yang akan digunakan untuk mendeteksi plagiarisme, user bisa memasukan dokumen pembanding dan dokumen yang akan dibandingkan. Selanjutnya pada Gambar 6 merupakan input dari n-gram, w-gram dan bilangan prima.

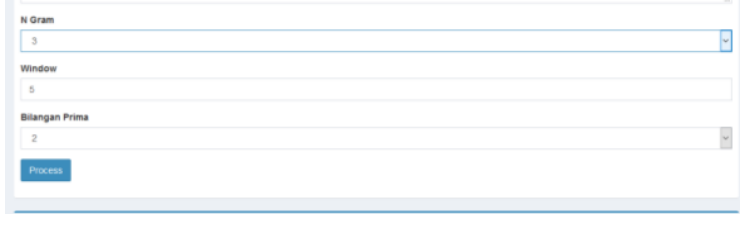

Gambar 6. Input N-gram, W-gram dan Bilangan Prima 
Gambar 6 menunjukan sebelum algoritma winnowing melakukan proses, user terlebih dahulu harus menentukan dan menginputkan $n$-gram, w-gram dan bilangan prima yang akan menentukan hasil akhir.

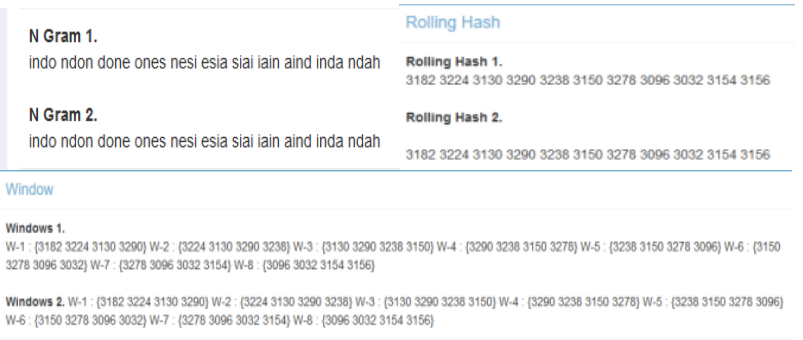

Gambar 7. Proses pembentukan N-gram, Rolling Hash, dan Pembentukan Window

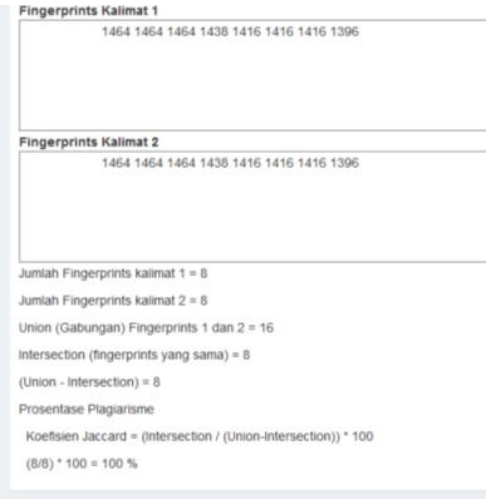

Gambar 8. Hasil akhir dari algoritma winnowing menggunakan Jaccard Similarity

Setelah ditentunakan nilai $n$-gram dan $w$-gram maka baru bisa dilakukan proses dari algoritma winnowing untuk mendeteksi plagiarisme. Gambar 5 sistem sudah melakukan proses pengecekan, sistem pertama akan menghilangkan karakter yang tidak relevan yaitu tokenizing (menghilangkan spasi dan tanda baca) dan cas folding (merubah huruf kapital menjadi huruf kecil). setelah itu sistem baru akan membentuk n-gram sepanjang $\mathrm{n}$, kemudian melakukan teknik hashing dan pembentukan window atau $w$-gram untuk menghasilkan fingerprint dari setiap dokumen dimana akan diambil nilai hash yang paling kecil untuk dijadikan fingerprint, jika terdapat dua atau lebih nilai hash yang paling kecil maka ambillah nilai hash yang paling kanan untuk dijadikan fingerprint.

Hasil akhir dari pendeteksi plagiarisme pada gambar 8 mampu menghasilkan persentasi sampai $100 \%$ dengan menggunakan Jaccard Similarity dari dokumen atau sample pada Gambar 6 dengan nilai $n$-gram 3 dan nilai $w$-gram 5 . Jika dibandingkan dengan metode $k$-gram yang digunakan pada [16] yang memperoleh kemiripan 83\%, hasil ini cukup andal. Dengan demikian, metode Jaccard Similarity memiliki prospek untuk digunakan dalam deteksi plagiat.

\section{Kesimpulan}

Dari hasil penelitian di atas dapat dipahami $n$-gram sangat mempengaruhi hasil dari similarity, penggunaan $n$-gram yang tepat sangat diperlukan. Tingkat drajat kesamaan pada dua dokumen/sample akan menghasilkan nilai similarity yang berbeda-beda jika nilai $n$-gram dan $w$ gram yang dimasukan itu berbeda beda nilainya. Jika nilai yang dimasukan kecil maka hasil drajat kesamaan memiliki hasil tinggi. Jika nilai $n$-gram dan $w$-gram yang dimasukan semakin besar maka nilai similarity atau drajat kesamaan antar dokumen akan memiliki hasil rendah. Nilai $n$-gram yang besar dapat menghasilkan similarity yang tinggi jika nilai w-gram atau window yang dimasukan bernilai kecil dan begitu juga sebaliknya. Jaccarad similarity yang digunakan untuk menghasilkan tingkat kesamaan antar dokumen juga cukup baik karna koefisien ini sederhana dengan mencari item yang sama dari dua dokumen kemudian dibagi dengan total item kedua dari penggabungan dua dokumen. Pendeteksi plagiarisme menggunakan metode $n$-gram dan jaccard Similarity terhadap algoritma winnowing cukup baik di gunakan untuk membandingkan kesamaan antara dua dokumen dan cukup baik digunakan untuk meminimalisir tindakan plagiarisme. Penelitian selanjutnya diharapkan dapat mendeteksi plagiarisme yang copy-paste dari karya ilmiah yang berbahasa inggris yang diterjemahkan ke dalam Bahasa Indonesi.

\section{Referensi}

[1]. Adik W. Mencegah dan Menanggulangi Plagiarisme di Dunia Pendidikan. Kesmas J. Kesehat. Masy. Nas. 2012; 6(5):195-200.

[2]. Iif A. M, Sunardi, Anton Y. "Perancangan Aplikasi Deteksi Plagiarisme Karya Ilmiah Menggunakan Algoritma Winnowing," in Seminar Nasional Serba Informatika. Samarinda. 2017;

[3]. Danang W Wicaksono, Mohammad Isa Irawan, dan Alvida Mustika Rukmi. Sistem Deteksi Kemiripan Antar Dokumen Teks Menggunakan Model Bayesian Pada Term Latent Semantic Analysis (LSA). Jurnal Sains dan Seni ITS. 2014: 2(3);A40-A45.

[4]. Reynald K. W, Khafiizh H. Penerapan Algoritma Winnowing Untuk Mendeteksi Kemiripan Teks pada Tugas Akhir Manusia. Techno.COM. 2016; 15(4): 303 311.

[5]. Komang R. Simple Query Suggestion untuk Pencarian Artikel menggunakan Jaccard Similarity. Jurnal Ilmiah Rekayasa dan Manajemen Sistem Informasi. 2017; 3(1): 30-34.

[6]. Agus R, S. Implementasi Algoritma Winnowing untuk Deteksi Kemiripan Text. Pelita Informatika Budi Darma. 2015; IX(1).

[7]. Eko N. Perancangan Sistem Deteksi Plagiarisme Dokumen Teks dengan Menggunakan Algoritma RabinKarp. Sekripsi. Malang. Universitas Braijaya. 2011;

[8]. Aisy M.R, Dyah A.I, Faisal R. Rancang Bangun Game Fighting Pawayangan Bahuraksa Arena. Jurnal Infrmatika Polinema.39-44. 
[9]. Erick A.L. Implementasi N-gram Technique dalam Deteksi Plagiarisme pada Tugas Mahasiswa. Jurnal Tematika. 2013; 1(2): 24-30.

[10]. Muhammad F, Imam M.I.S, Dedy K. Sistem Rekomendasi Hasil Pencarian Artikel menggunakan Metode Jaccard's Coefficient. Jurnal Transistor Elektro dan Informatika (TRANSSISTOR EI). 2017; 2(1):1-14.

[11]. Sugiyamto, Bayu S, Aris S. Analisa Performa Metode Cosine dan Jaccard pada Pengujian Kesamaan Dokumen. Jurnal Masyarakat Informatika. 5(10):1-8.

[12]. Anton Y, Abdul D.D. Implementation of Pattern Matching Algorithm for Portable Document Format. Int. J. Adv. Comput. Sci. Appl. 2017; 8(11):509-512.

[13]. Ana K, Wayan S.W. Perbandingan Pendekatan Deteksi Plagiarism Dokumen dalam Bahasa Inggris. Proceeding, Seminar Ilmiah Nasional Komputer dan Intelijen (KOMMIT 2008). Depok. 2008; 284-291.
[14]. Muhammad R. Rancang Bangun Aplikasi Pendeteksi Penjiplakan Dokumen menggunakan Algoritma Biword Winnowing. Sekripsi. Pekanbaru Riau. Universitas Islam Negeri SLTAN Syarif Khasin; 2013;

[15]. Jody, Agung T. W, Anditya A. Analisis dan Implementasi Algoritma Winnowing dengan Synonym Recognition pada Deteksi Plagiarisme untuk Dokumen Teks Berbahasa Indonesia. e-Proceeding Eng. 2015; 2(3):7674-768.

[16]. Mudafiq R Pratama, EB Cahyono, GI Marthasari, "Aplikasi Pendeteksi Duplikasi Dokumen Teks Bahasa Indonesia Menggunakan Algoritma Winnowing Dengan Metode K-Gram Dan Synonym Recognition." Jurusan Teknik Informatika Universitas Muhammadiyah Malang, 2012. 